\title{
COMPORTAMENTO HÍDROGEOQUÍMICO DOS ISÓTOPOS DE URÂNIO EM ÁGUAS DE LINDÓIA (SP), BRASIL
}

\author{
ENE GLORIA DA SILVEIRA* \& DANIEL MARCOS BONOTTO**
}

\begin{abstract}
RESUMO O presente trabalho tem por objeti vo investigar o comportamento geoquímico dos isótopos de urânio, ${ }^{23} \mathrm{U}, \mathrm{e}{ }^{238} \mathrm{U}$, nas á guas das fontes da cidade de Á quas de Lindóia, Estado de São Paulo, visando contribuir com 0 conhecimento sobre a radioatividade natural dessas agguas. Para a sua realização foi necessário efetuar a determinação do teor de Urânio-238 e razão de atividade ${ }^{234} \mathrm{U}^{238}$; U nas águas das seguintes fontes e poços tubulares profundos localizados no perímetro urbano e vizinhanças de Águas de Lindóia:Glória, Filomena, Levíssima I, Levíssima II, Beleza, São Roque, Lindália e Santa Isabel. Além das análises isotópicas de urânio, vários parâmetros adicionais foram determinados para subsidiar a interpretacão dos resultados, como $\mathrm{pH}$, Eh, temperatura, teor de oxigénio dissolvido e pressão parcial do gás* carbónico dissolvido. Os resultados obtidos mostram que o urânio está sendo transportado na forma dos complexos $\mathrm{UO}_{2} \mathrm{CO}_{3}$ e $\mathrm{UO}_{2}\left(\mathrm{CO}_{3}\right)_{2}{ }^{2-}$ e que o modelo isotópico disponível em literatura para a prospecção hidrogeoquímica de depósitos de urânio é válido nos aquíferos estudados.
\end{abstract}

Palavras-chaves:isótopos. urânio, áeuas subterrâneas. À guas de Lindóia

\begin{abstract}
HYDROGEOCHEMICAL BEHAVIOR OF URANIUM ISOTOPES AT ÁGUAS DE LINDÓIA (SP), BRASIL An investigation concerning the geochemical behavior of uranium isotopes ${ }^{234} U$ and ${ }^{238} U$ ) was performed on spring waters from Aguas de Lindoia city, Sao Paulo State, in order to improve the knowledge of natural radioactivity of these waters.Measurements of Uranium-238 contents and ${ }^{234} U{ }^{338} U$ activity ratios in groundwaters were performed on the following springs and wells in the urban area and surroundings of Aguas de Lind6ia:Gloria, Filomena, Levissima I, Levissima II, Beleza, São Rogue, Lindália and Santa Isabel. Several additional parameters were evaluated in the same waters as an aid to interpret the data, for instance, $\mathrm{pH}$, Eh, temperature, dissolved oxygen content and partial pressure of dissolved carbon dioxide. The data show that uranium is being mobilized as $\mathrm{UO}_{2} \mathrm{CO}_{3}$ and $\mathrm{UO}_{2}\left(\mathrm{CO}_{3}\right)_{22}$ - complexes and that the isotopic model available in literature for the hydrogeochemical prospection of $U$ deposits is valid on the studied aquifers.
\end{abstract}

Keywords:isotopes, uranium, groundwaters, Águas de Lindóia

INTRODUÇÃo Os principais radionuclídeos que contribuem para a radioatividade do meio ambiente são o Potássio-40, o Rubídio-87 e os que formam as séries do Urânio-238, Urânio-235 e Tório-232; sua origem está relacionada com os processos de nucleossíntese, sendo suas meias-vidas da ordem de grandeza da idade da Terra $\left(4,5 \times 10^{9}\right.$ anos). Há vários anos, crescente interesse passou a ser dirigido aos isótopos de urânio ${ }^{234} \mathrm{U}$ e ${ }^{238} \mathrm{U}$, de ocorrência natural, que comecaram a ser empregados em Geociências com finalidades diversas (Cherdyntsev et al. 1955, Chalov 1959, Osmond et al. 1968, Osmond \& Cowart 1976, Cowart \& Osmond 1980). O ${ }^{234} \mathrm{U}$ é produto de decaimento do ${ }^{238} \mathrm{U}$ e, desde o início das pesquisas, caracterizou-se a existência de desequilíbrio entre esses isótopos em águas naturais (Blanchard 1965).

Num dos primeiros trabalhos com enfoque hidrológico, Osmond et al. (1968) estudaram um sistema simples de água subterrânea e sugeriram que 0 teor de urânio dissolvido e a razão de atividade ${ }^{234} U /{ }^{238} U$ fossem consideradas propriedades conservativas; admitindo o sistema como sendo de diluição isotópica, esses autores deduziram as proporções das águas de diferentes procedências que contribuiam numa mistura. Pesquisas posteriores foram desenvolvidas, fornecendo outras interpretações hidrológicas aos resultados obtidos para as razões ${ }^{234} \mathrm{U} /{ }^{238} \mathrm{U}$ e concentrações de urânio nas águas, conforme se verifica por exemplo em Osmond \& Ivanovich (1983).

O presente trabalho tem por objetivo investigar o comportamento geoquímico dos isótopos ${ }^{234} \mathrm{U}$ e ${ }^{238} \mathrm{U}$ nas águas subterrâneas da estância hidromineral da cidade de Águas de Lindóia, Estado de São Paulo (Fig. 1). Essas águas são conhecidas desde o século XVIII, quando passaram a ser utilizadas para fins terapêuticos. A cidade teve sua origem na antiga sesmaria, cujas terras foram doadas por Manoel de Castro, sendo que dentre os eventos importantes de sua história cita-se a visita de Madame Curie à estância em 1928 e a construção do Balneário Prof. Dr. João Aguiar Pupo, concluída em 1959.

Em que se pese o interesse suscitado pela radioatividade natural dessas águas, ressalta-se que ainda é escasso o conhecimento disponível, uma vez que a maioria das análises publicadas refere-se à presença de gás radônio dissolvido. Nesse sentido, elas tem sido classificadas e comercializadas como radioativas e fracamente radioativas em termos de Unidade Mache $(1000 \mathrm{pCi} / 1=2,75$ mache $)$, registrando-se, por exemplo, os seguintes valores em alguns rótulos:Levíssima I e II = 16 UM, Lindália $=10,11 \mathrm{UM}$, Santa Isabel $=5,2 \mathrm{UM}$ e São Roque $=11,52$ UM.

CARACTERÍSTICAS GERAIS DA ÁREA DE ESTUDO Águas de Lindóia, segundo o Censo Demográfico de 01/09/91, possui 11997 habitantes, residindo no turismo e setor hoteleiro sua principal atividade económica, com destaque também para a indústria de engarrafamento de águas minerais, com producão de $18321000 \mathrm{I} / \mathrm{ano} \mathrm{em}$ 1987, correspondente ao quarto lugar no Estado de São Paulo e 8\% da produção no Brasil (DNPM 1988).

Segundo Grossi Sad et al. (1982), as formas do relevo na área são separáveis em:cristas alongadas NE- SW, de escarpas abruptas, em quartzitos, milonitos e gnaisses; morros arredondados ou ovalados de encosta íngreme, em gnaisses e migmatitos; morros arredondados de encostas suaves e forma de meia laranja, em granitos e outros litotipos; vales curtos, retilíneos, adaptados a falhas verticalizadas. O sistema de relevo e a altitude (variando de 945 a $1200 \mathrm{~m}$ ) da região condicionam o clima e a pluviosidade, sendo a temperatura média em torno de $20^{\circ} \mathrm{C}$. Segundo a classificação de Köppen, o clima da área é do tipo Cwarmesotérmico com inverno seco e verão quente. A pluviosidade média anual varia de 1143 a $2023 \mathrm{~mm}$, com

\footnotetext{
* - Departamento de Geografia-Fundação Universidade Federal de Rondônia-Av. Presidente Dutra, nº 2965-78900-500, Porto Velho, RO, Brasil

**- Departamento de Petrologia e Metalogenia-Instituto de Geociências e Ciências Exatas-Universidade Estadual Paulista Júlio de Mesquita Filho-UNESP-Av. 24-A, n 1515-Caixa Postal 178-13506-900, Rio Claro, SP, Brasil-Telefone (019) 5340522 FAX (019) 5249644
} 


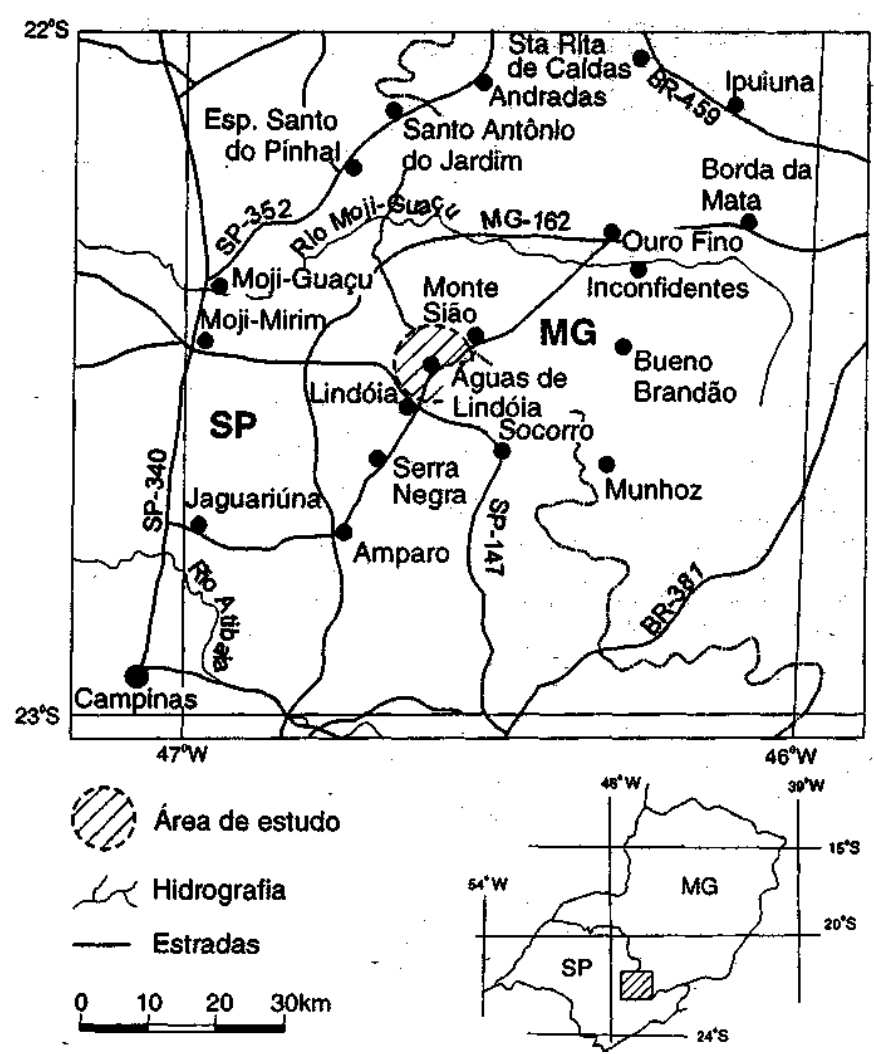

Figura 1-Localização da área estudada e vias de acesso. Figure 1-Location of the studied área and routes of access.

máximas durante a primavera e verão (maio e setembro) (DAEE 1981). Os lineamentos de fraturas controlam o sistema de drenagem situado a sudeste e noroeste da área, o qual é classificado como dendrítico, sendo pouco frequentes os vales encaixados e as planícies aluvionares. As quedas d'água e/ ou corredeiras são frequentes devido a grande variação topográfica, concordantemente com o relevo,

A região sofreu, ao longo do tempo, evolução polifásica e policíclica em seus aspectos metamórficos, deformativos, magmáticos e migmatíticos, tornando dificil a sua delimitação, reconstituição das sequências e caracterização primária dasTochas. Esses eventos atuaram na região desde o Arqueano até o Proterozóico Superior, englobando rochas caracterizadas por metamorflsmo de alto grau, geralmente de fácies granulito e anfibolito (Almeida \& Hasui 1984). Essas rochas apresentam variação na composição e granulometria, sendo os quartzitos, de granulação fina a média, mais quebradiços que os migmafitos e gnaisses, de granulação média. Uma vez que a capacidade de se fraturar de um litotipo cristalino está relacionada com sua melhor ou pior qualidade como aquífero, verifica-se que esta propriedade pode justificar as observações de Del Rey (1989) de que na área estudada os quartzitos sãa unidades litológicas que apresentam as melhores fontes produtoras de água (vazões mais elevadas).

Para fins de estudos hidrogeológicos, Yoshinaga (1990) procedeu um levantamento das ocorrências de águas subterrâneas existentes na área de estudo, tendo efetuado um cadastro de 19 poços tubulares profundos e 24 nascentes nos municípios de Lindóia e Águas de Lindóia, destinados ao uso comum e engarrafamento de águas minerais e explorados por empresas mineradoras, estado e prefeituras.

A maioria das amostras de águas subterrâneas coletadas nesta investigação consiste de surgências naturais em quartzito, um dos grupos litológicos de maior representatividade na área (Fig.2). Tal é o caso para as fontes Filomena, São Roque,
Beleza, Glória, Levíssima I e II, cujas vazões variam entre 0,5 e 7,8 $1 \mathrm{~s}^{-}{ }^{-}$(Yoshinaga 1990). No balneário Prof. Dr. João de Aguiar Pupo e proximidades estão situadas as seguintes fontes:Filomena- localiza-se fora do Balneário e já foi engarrafada e comercializada pelo Governo do Estado de São Paulo e atualmente encontra-se desativada, atendendo apenas a população local; São Roque- abastece o Balneário (como piscina termal) e bebedouro público; Beleza-localiza-se dentro do Balneário e atende a população local; Glória- a nascente situa-se dentro do Balneário e atualmente abastece o Hotel Glória. As fontes Levíssima I e II são comercializadas pela concessionária Empresa de Águas São Lourenço S/A. Embora Lindália e Santa Isabel tenham sido referidas como fontes, na realidade tratam-se de poços tubulares profundos perfurados pelo método de percussão, cujas profundidades são $20 \mathrm{~m}$ (Lindália) e $72 \mathrm{~m}$ (Santa Isabel). O manto de alteração no primeiro caso é de $5 \mathrm{~m}$ e nó segundo é de $30 \mathrm{~m}$, após o que as perfurações atingiram mígmatito, o outro grupo litológico de maior representatividade na área (Yoshinaga 1990). Lindália é comercializada pelo Grupo Empresarial Arlindo Siracusa Filho, concessionário de Águas de Lindóia Mineração Comércio Ltda. Santa Isabel é comercializada pela concessionária Água Mineral Legítima Lindóia Ltda.

MATERIAIS E MÉTODOS Visando a amostragem para análise isotópica de urânio, foram selecionados os oito pontos de coleta referidos na Figura 2, situados na área urbana e vizinhanças do município de Águas de Lindóia, os quais foram escolhidos por serem hidroquimicamente conhecidos, por apresentarem localização de fácil acesso para a coleta de amostras e por estarem relacionados com diferentes litotipos.

A campanha de coleta de amostras de água para análise do teor de urânio dissolvido e razão isotópica ${ }^{234} \mathrm{U} /{ }^{238} \mathrm{U}$ foi efetuada por meio da utilização de recipientes de polietileno com capacidade para 20 litros. Por ocasião da coleta, efetuaram-se determinações complementares in situ, envolvendo os parâmetros $\mathrm{pH}$, Eh, temperatura e teor de oxigénio dissolvido, os quais permitem um melhor conhecimento das condições físico-químicas do ambiente de circulação das águas. Para a determinação do oxigénio dissolvido utilizou-se o oxímetro analógico Analion OX900, o qual também dispõe de um sensor que detecta a temperatura da água. Para a leitura do $\mathrm{pH}$ utilizou-se um medidor portátil digital da Digimed, o qual foi acoplado a um eletrodo combinado de vidro (modelo V-620A da Analion); a determinação do Eh foi efetuada com o mesmo medidor, porém, a ele foi acoplado um eletrodo combinado de platina.

Os recipientes utilizados na amostragem foram lavados com ácido clorídrico em solução $1: 1$, numerados, pesados, enxaguados em água destilada e, finalmente, secos. No ato da coleta abluiram-se os frascos com a própria água amostrada, tendo sido evitado a contaminação com outras impurezas e/ ou contato com material orgânico.

Após a coleta, para proceder a análise de urânio, cada amostra foi acidificada com ácido clorídrico a fim de evitar a precipitação de ferro no recipiente; a acidificação foi controlada para manter o $\mathrm{pH}$ abaixo de 2 (Osmond \& Cowart 1976). Uma vez transportadas ao laboratório, as amostras foram filtradas em membrana Millipore de 0,45 um.

A técnica utilizada para extração do urânio das águas baseou-se na metodologia empregada por Bonotto (1986), descrita primeiramente por Blanchard (1965), Miyake et al. (1966), Moore \& Sackett (1964) e Osmond \& Cowart (1976). Em resumo, após adição de $33,89 \mathrm{dpm}$ do traçador ${ }^{232} \mathrm{U}^{228} \mathrm{Th}$ em equilíbrio radioativo, ela envolveu as seguintes etapas:coprecipitação de $\mathrm{U}$ com $\mathrm{Fe}(\mathrm{OH})_{3}$; extração de $\mathrm{Fe}^{3+}$ com éter isopropílico; eliminação de Th através de passagem da solução contendo $U$ em resina de troca aniônica fortemente básica e eletrodeposição de U em disco de aço inoxidável. 


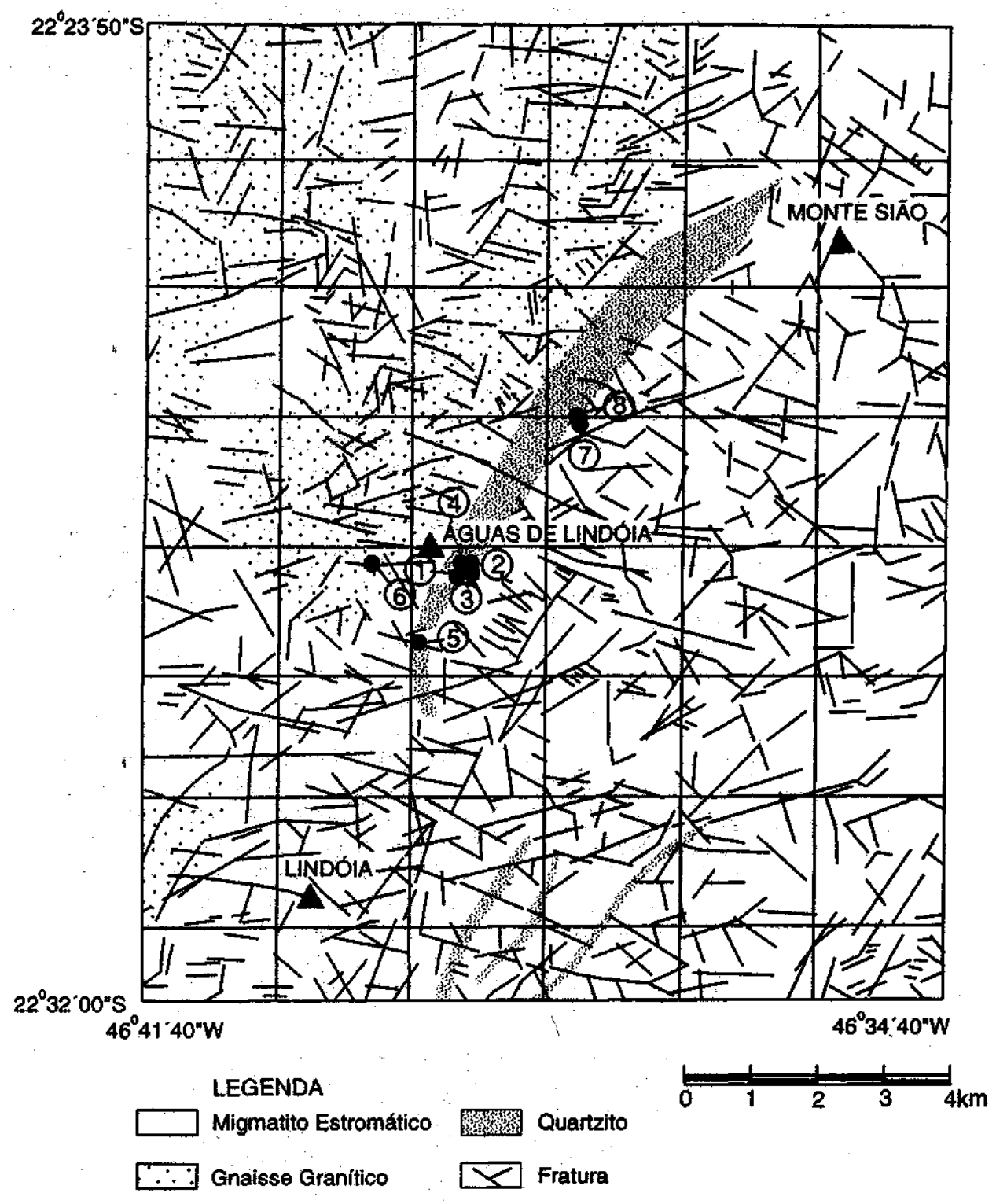

$\begin{array}{ll}\text { 1 - Sāo Roque } & 5 \text { - Santa isabel } \\ \text { 2- Filomena } & 6 \text { - Lindália } \\ \text { 3- Beleza } & 7 \text { - Levissima } \\ \text { 4-Glória } & 8 \text { - Levíssima }\end{array}$

Figura 2-Mapa geológico-estrutural simplificado da área estudada e pontos de amostragem de águas subterrâneas para análise isotópica de urânio. Adaptado de Del Rey (1989).

Figure 2-A simplified geológical and structural map of the studied area showing sampling points of groundwaters for analysis of uranium isotopes. Adapted from Del Rey (1989).

Determinou-se a concentração de U e razão isotópica ${ }^{234} U /^{238} \mathrm{U}$ através de espectrometria alfa via detector semicondutor de barreira de superfície, sendo a aquisição de dados efetuada em Analisador Multicanal de 1024 canais.

A obtenção do teor de urânio foi efetuada com base no princípio de diluição isotópica, de acordo com o descrito por Bonotto (1986), Para a quantidade de traçador utilizada, é possível avaliar a concentração de urânio através da seguinte equação:

$$
\mathrm{U}=\frac{45,8\left(\mathrm{~T}_{238}-1,2410\right)}{\mathrm{V}\left(\mathrm{T}_{232}-1,9165\right)}
$$

onde $\mathrm{V}$ é 0 volume de água utilizado na análise, $\mathrm{T}_{238}$ é a taxa de contagem (em cph) no pico do ${ }^{238} \mathrm{U}$ e $\mathrm{T}_{232}$ é a taxa de contagem (em cph) no pico do. De acordo com a equação, o teor de urânio é expresso em $\mu \mathrm{g} / 1$ ou ppb, sendo a razão isotópica ${ }^{234} \mathrm{U} /{ }^{238} \mathrm{U}$ obtida diretamente a partir da taxade contagem nos picos do ${ }^{234} \mathrm{U}$ e ${ }^{238} \mathrm{U}$. A taxa de contagem do fundo radioativo nas regiões do ${ }^{238} \mathrm{U},{ }^{234} \mathrm{U}$ e ${ }^{232} \mathrm{U}$ correspondem, respectivamente, a 1,24 cph, $0,55 \mathrm{cph}$ e 1,92 cph. Na Tabela 1 constam os resultados obtidos nesta investigação, bem como os dados referentes às análises químicas das águas estudadas conduzidas por outros autores. 


\section{DISCUSSÃO}

Caracterização Hidroquímica

Embora a temperatura das águas das fontes estudadas seja suscetível de modificação em decorrência das oscilações climáticas (a campanha de coleta foi realizada durante o outono, quando a pluviosidade é mínima), com base no Código de Águas Minerais referido por DNPM (1987), é possível constatar que, à exceção de Levíssima I e II que são fontes frias (temperatura menor que $25^{\circ} \mathrm{C}$ ) e de Santa Isabel e Lindália que são poços, as demais nascentes são hipotermais, pois, os valores obtidos para a temperatura situam-se entre 25 e33(C.

O teor de oxigénio dissolvido nas águas subterrâneas estudadas varia de 4,5 a $11 \mathrm{mg} / 1$, parâmetro que possibilita estimar a pressão parcial do $\mathrm{O}_{2}$ nas amostras, com base na lei de Henry (Brownlow 1979) aplicada à reação :

$$
\mathrm{O}_{2(\mathrm{~g})} \leftrightarrow \mathrm{O} 2(\mathrm{aq})
$$

onde a constante de Henry a $25{ }^{\circ} \mathrm{C}$ corresponde a $10^{-2,9}$ $\mathrm{mol} / 1 \mathrm{~atm}$ (Stumm \& Morgan 1970). Conforme ilustrado na Figura 3, os valores obtidos situam-se entre $10^{-0,95}$ e $10^{-0,56}$ atm, denotando que é alta a pressão parcial de $\mathrm{O}_{2}$ dissolvido em todas as amostras analisadas (praticamente corresponde à pressão parcial do oxigénio em água saturada de ar), ou seja, situa-se próximo do limite superior de estabilidade da água, caracterizando que o ambiente está enriquecido em oxigénio, o que poderia indicar que ele apresenta caráter oxidante.

Vários fatores podem estar contribuindo para a presença de $\mathrm{O}_{2}$ dissolvido nas amostras:reações químicas e biológicas, contato direto com o ar, mistura de águas profundas com águas superficiais e baixa profundidade de circulação das águas. Além disso, como as fraturas, fendas e diáclases são comuns na área (a ocorrência das fontes está relacionada com essas estruturas), a mobilidade do oxigénio é facilitada, ocorrendo a sua solubilização nas águas em seu trajeto até a surgência.

Se os dados obtidos para $\mathrm{pH}$ e Eh são inseridos no diagrama relativo a esses parâmetros proposto por Krauskopf (1972) (Fig. 4), então, é possível notar que o ambiente das águas das fontes varia de transicional para redutor. Assim, o caráter oxidante do ambiente de circulação das águas evidenciado pelos dados de $\mathrm{O}_{2}$ dissolvido não encontra suporte quando se leva em conta as espécies iônicas dissolvidas (dados de potencial redox e $\mathrm{pH}$ ), confirmando as observações de Brownlow (1979), Faure (1991) e Stumm \& Morgan (1970), que sugerem que o teor de $\mathrm{O}_{2}$ dissolvido não é um parâmetro adequado para definir se o ambiente é oxidante ou redutor. Para justificar sua proposição, Brownlow (1979) refere-se a uma situação de um sistema aquático anaeróbico natural, caracterizado por um potencial redox Eh de $+360 \mathrm{mV}$ e $\mathrm{pH} 7$, para o qual determinou uma baixa concentração de $\mathrm{O}_{2}$ dissolvido correspondente a $10^{-17} \mathrm{M}$ e considerou que a saturação da água com esse gás proporciona apenas um acréscimo de $90 \mathrm{mV}$ no valor de Eh, indicativo de que ele exerce pouca (ou nenhuma) influência no potencial redox, parâmetro que seria afetado principalmente pela composição da solução, isto é, espécies iônicas dissolvidas.

Conforme observaram Todd (1980) e Hem (1959) a condutividade elétrica e os sólidos totais dissolvidos estão muitas vezes diretamente relacionados, situação constatada para as amostras consideradas nesta investigação, uma vez que o coeficiente de correlação de Pearson determinado foi de 0,86 .

Os resultados das análises dos principais cátions dissolvidos nas águas estudadas mostraram que o maior teor observado é o de cálcio para a amostra da Fonte São Roque, sendo que dentre os ânions dissolvidos destaca-se a predominância de bicarbonato em todas as amostras.

Tabela 1- Resultados das análises de amostras de águas subterrâneas de Águas de Lindóia (SP).

Table l- Results of analyses of groundwater samples from Á guas de Lindóia (SP).

\begin{tabular}{|c|c|c|c|c|c|c|c|c|c|}
\hline \multicolumn{10}{|c|}{ Fonte / Poço } \\
\hline Parâmetro & Unidade & Săo Roque & Filomena & Beleza & Glória & $\begin{array}{l}\text { Santa } \\
\text { Isabel }\end{array}$ & Lindóia. & $\begin{array}{l}\text { Levissima } \\
\text { I }\end{array}$ & $\begin{array}{l}\text { Levíssima } \\
\text { II }\end{array}$ \\
\hline Temperatura & ${ }^{\circ} \mathrm{C}$ & 27 & 26 & 27 & 26 & 21 & 21 & 20 & 19 \\
\hline $\mathrm{pH}$ & - & 7,20 & 6,80 & 7,30 & 6,90 & 6,48 & 6,20 & 5,72 & 5,50 \\
\hline Eh & $m V$ & 70 & 97 & 61 & 92 & 131 & 168 & 215 & 229 \\
\hline Condut. ${ }^{1}$ & $\mu \mathrm{S} / \mathrm{cm}$ & 99 & 107 & 130 & 100 & 81 & 92 & 9 & 12 \\
\hline $\mathrm{O}_{2}$ dissolvido & $\mathrm{mg} / \mathrm{l}$ & 9,8 & 9,0 & 9,2 & 11,0 & 7,8 & 4,5 & 7,0 & 6,0 \\
\hline $\mathrm{CO}_{2}$ dissolv. ${ }^{\prime}$ & $\mathrm{mg} / 1$ & 4,4 & 4,4 & 4,4 & 11,0 & 3,8 & 42,9 & 28,6 & 28,6 \\
\hline Sodio ${ }^{2}$ & $\mathrm{mg} /$ & 1,10 & 1,32 & 0,77 & 1,83 & 1,70 & 7,02 & 0,50 & 0,50 \\
\hline Potássio ${ }^{2}$ & $\overline{\mathrm{mg} /}$ & 2,00 & 2,80 & 2,50 & 2,20 & 1,80 & 4,50 & 2,10 & 2,30 \\
\hline Cálcio $^{2}$ & $\overline{\mathrm{mg} / \mathrm{l}}$ & 11,66 & 10,30 & 10,80 & 8,28 & 4,90 & 6,76 & 0,77 & 0,50 \\
\hline Magnésio $^{2}$ & $\mathrm{mg} /$ & 3,30 & 4,30 & 5,80 & 3,20 & 5,45 & 1,81 & 0,36 & 0,31 \\
\hline Cloreto $^{1}$ & $\mathrm{mg} / \mathrm{l}$ & 0,50 & 0,12 & 0,80 & 0,38 & 0,50 & 0,50 & 0.12 & 0,01 \\
\hline Nitrato ${ }^{1}$ & $\mathrm{mg} / \mathrm{l}$ & 0,84 & 0,02 & 0,02 & 0,30 & 0,50 & 0,65 & 0,12 & 0,09 \\
\hline Bicarbonato ${ }^{\prime}$ & $\mathrm{mg} / \mathrm{l}$ & 54,00 & 67,10 & 67,10 & 51,85 & 48,80 & 48,80 & 6,10 & 6,10 \\
\hline Sulfato' & $\mathrm{mg} / \mathrm{l}$ & 0,01 & 0,90 & 2,00 & 1,19 & $0,0 \mathrm{i}$ & 0,33 & 0,14 & 0,15 \\
\hline Sol.Tot.Dis. ${ }^{1}$ & $\mathrm{mg} /$ & 74,54 & 38,11 & 88,99 & 67,13 & 59,00 & 85,81 & 10,96 & 11,00 \\
\hline Urânio $^{3}$ & $\mu \mathrm{g} / \mathrm{l}$ & 0,13 & 0,13 & 0,21 & $<0,001$ & 0,07 & 0,06 & 0,16 & 0,51 \\
\hline $\mathrm{RA}^{234} \mathrm{U}^{238} \mathrm{U}^{3}$ & - & 3,04 & 2,08 & 1,62 & - & 2,12 & 3,76 & 2,28 & 0,81 \\
\hline
\end{tabular}

${ }^{1}$ Conforme Yoshinaga (1990).

${ }^{2}$ Valores médios calculados a partir dos dados de Yoshinaga (1990), Hurter (1988) e Del Rey (1989).

${ }^{3}$ Incerteza de $\pm 10 \%$ correspondente a um desvio padrão de $1 \sigma ; \mathrm{RA}=$ razão de atividade. 
Para avaliar o erro percentual relativo aos dados dos principais cátions e ânions compilados na Tabela 1, transformaram-se os valores expressos em $\mathrm{mg} / 1$ para $\mathrm{mEq} / 1$ e empregouse a seguinte equação:

$$
\mathrm{e}(\%)=\frac{\text { soma.dos.cátions. }- \text {.soma.dos.ânions }}{\text { soma.dos.cátions. }+ \text {.soma.dos.ânios }} X 100
$$

Os valores obtidos para todas as amostras são menores que $7 \%$, considerados apropriados por inúmeros pesquisadores para expressar o equilíbrio catiônico e aniônico, por exemplo, Fenzl (1988).

Para efetuar a classificação química das águas estudadas com base nos dados compilados foi escolhido o-diagrama de Piper (1944) para a representação gráfica, por fornecer uma boa visualização da fácies química e por se constituir no diagrama mais comumente utilizado. Assim, de acordo com o diagrama de Piper ilustrado na Figura 5 as águas estudadas podem ser classificadas da seguinte maneira:biearbonatada cálcio-sódica (Lindália), bicarbonatada eálcio-potássica (Beleza), bicarbonatada potássica (Levíssima I e II), bicarbonatada magnesiana (Santa Isabel) e bicarbonatada cálcica (Glória, Filomena e São Roque).

\section{Urânio Dissolvido e Qualidade das Águas}

urânio possui várias valências $(2+, 3+, 4+, 5+$ e $6+)$, ocorrendo mais comumente na natureza nos estados de oxidação $4+$ e $6+$. $O$ íon uranoso $\left(\mathrm{U}^{4+}\right)$ tem raio iônico $1,05 \mathrm{~A}$ e potencial iônico 4; o $\mathrm{U}^{6+}$ é quase sempre encontrado na forma do radical uranila $\mathrm{UO}_{2}{ }^{2+}$, tendo como raio iônico 7 (Rõsler \& Lange 1972). O campo de estabilidade do $\mathrm{UO}_{2}{ }^{2+}$ é bem mais amplo que o do $\mathrm{U}^{4+}$ e, no estado de valência $6+, 0$ urânio forma complexos solúveis com os ânions comuns presentes nas águas naturais. Para pH's entre 2 e 4 , os principais complexos de uranila são formados com ânions de flúor. Para $\mathrm{pH}$ 's entre 4 e 7,5, os principais complexos de uranila são formados com ânions de carbonato. Em menor grau, existem contribuições dos ânions de sulfato e cloro para a formação de complexos com o radical uranila (Langmuir 1978). Esses complexos apresentam maior mobilidade que os formados com o íon uranoso $\left(\mathrm{U}^{4+}\right)$, por ser mais elevado o potencial iônico do urânio na valência $6+$ (Goldschmidt 1954). Dentre esses ânions, o bicarbonato é o dominante nas águas estudadas e, por isso, é importante levar em conta a presença do gás carbónico para avaliação dos possíveis complexantes para o íon uranila. A partir dos dados inseridos na Tabela 1 foi possível estimar a pressão parcial de $\mathrm{CO}_{2}$ nas amostras com base na Lei de Henry (Brownlow 1979) aplicada à reação:

$$
\mathrm{CO}_{2(\mathrm{~g})} \leftrightarrow \mathrm{CO}_{2(\mathrm{aq})}
$$

onde a constante de Henry corresponde a $0,033 \mathrm{~mol} / 1$. atm (a $25^{\circ} \mathrm{C}$ ). Os valores obtidos correspondem a pressões parciais que variam de $10^{-1,5}$ a $10^{-2,5} \mathrm{~atm}$, média de $10^{-1,9} \mathrm{~atm}$. Como a média é próxima ao valor típico de $10^{-2}$ atm para as águas subterrâneas, os dados de $\mathrm{pH}$ e Eh obtidos para as amostras podem ser inseridos no diagrama Eh-pH de Langmúir (1978) representativo dos campos de estabilidade do $\mathrm{U}^{4+} \mathrm{U}^{5+} \mathrm{e} \mathrm{UO}_{2}^{2+}$ e apropriado a esta pressão parcial. Conforme sugere o diagrama ilustrado na Figura 6, o urânio pode estar sendo transportado nas águas estudadas na forma dos complexos $\mathrm{UO}_{2}$ $\mathrm{CO}_{3}{ }^{0}$ e $\mathrm{UO}_{2}\left(\mathrm{CO}_{3}\right) 2^{2-}$.

O urânio no ambiente hidrológico é de especial interesse devido sua importância económica, química e radiológica, inclusive de alguns de seus nuclídeos filhos, por exemplo, o ${ }^{226} \mathrm{Ra}$. Numa escala global, as concentrações de urânio solúvel geralmente variam de 0,1 a $10 \mu \mathrm{g} / 1 \mathrm{em}$ rios, lagos e águas subterrâneas (Osmond \& Cowart 1976). As determinações de radioati vidade alfa total tem sido empregadas para estabelecer limites permitidos para o público. Os limites de contaminação são indicados assumindo que toda a atividade alfa deve-se ao ${ }^{226} \mathrm{Ra}$ devido o seu alto grau de radiotoxicidade, grande tendência de fixar-se nos ossos, curta meia- vida de 1622 anos relativamente à do urânio, e grande potencial de produzir dano

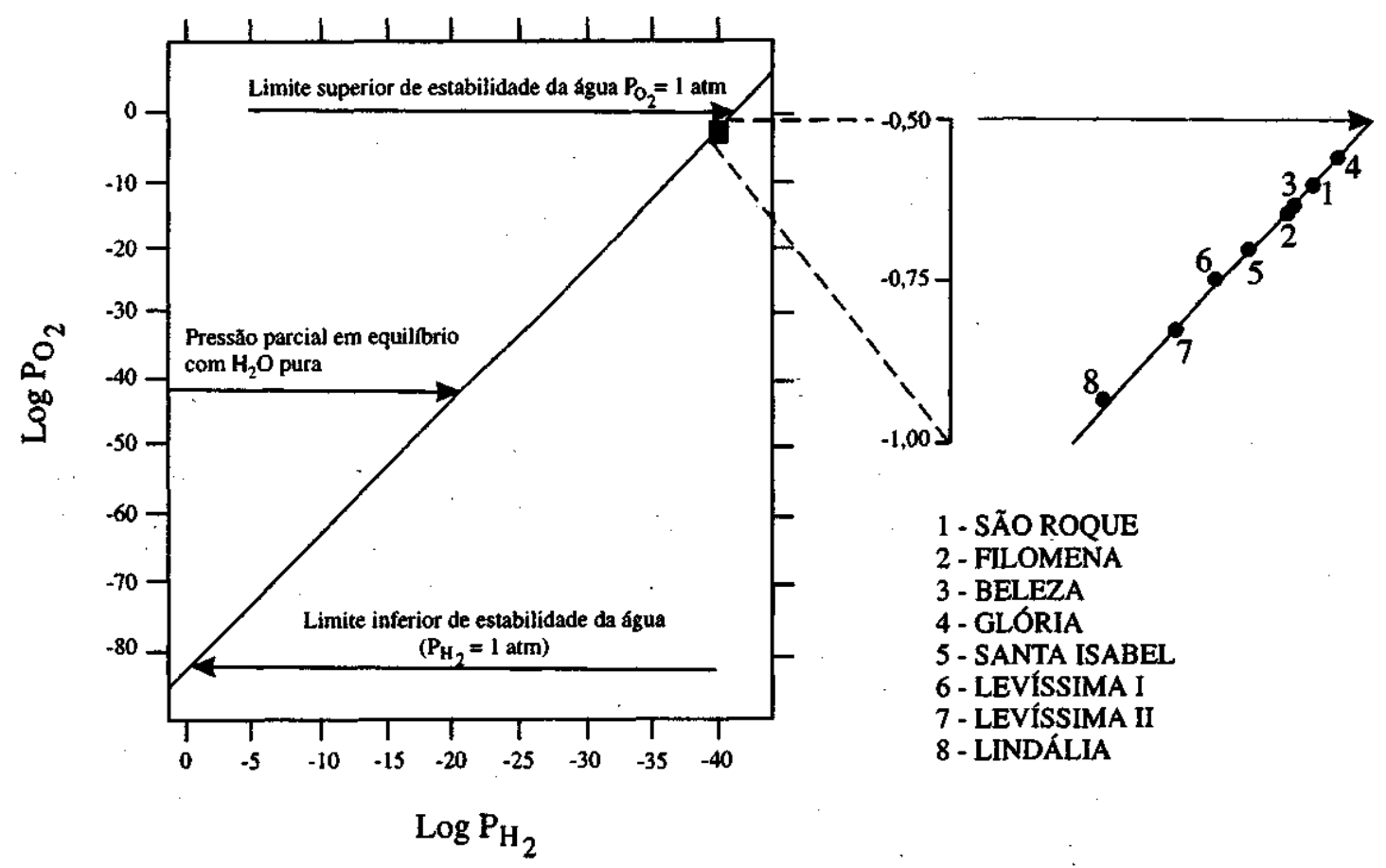

Figura 3-Representação dos dados obtidos para as águas subterrâneas de Águas de Lindóia (SP) no diagrama de pressão parcial de oxigénio e hidrogênio em equilíbrio com a água à temperatura de $25^{\circ} \mathrm{C}$ e pressão total de 1 atmosfera (Garrels 1960). Figure 3- $\mathrm{PO}_{2}$ and $\mathrm{PH}_{2}$ of groundwater samples from Á guas de Lindó ia (SP) plotted $\mathrm{m}$ a diagram of partialpressure of oxygen and hydrogen in equilibrium with water at temperature of $25^{\circ} \mathrm{C}$ and total pressure of 1 atmosphere (Garrels 1960). 


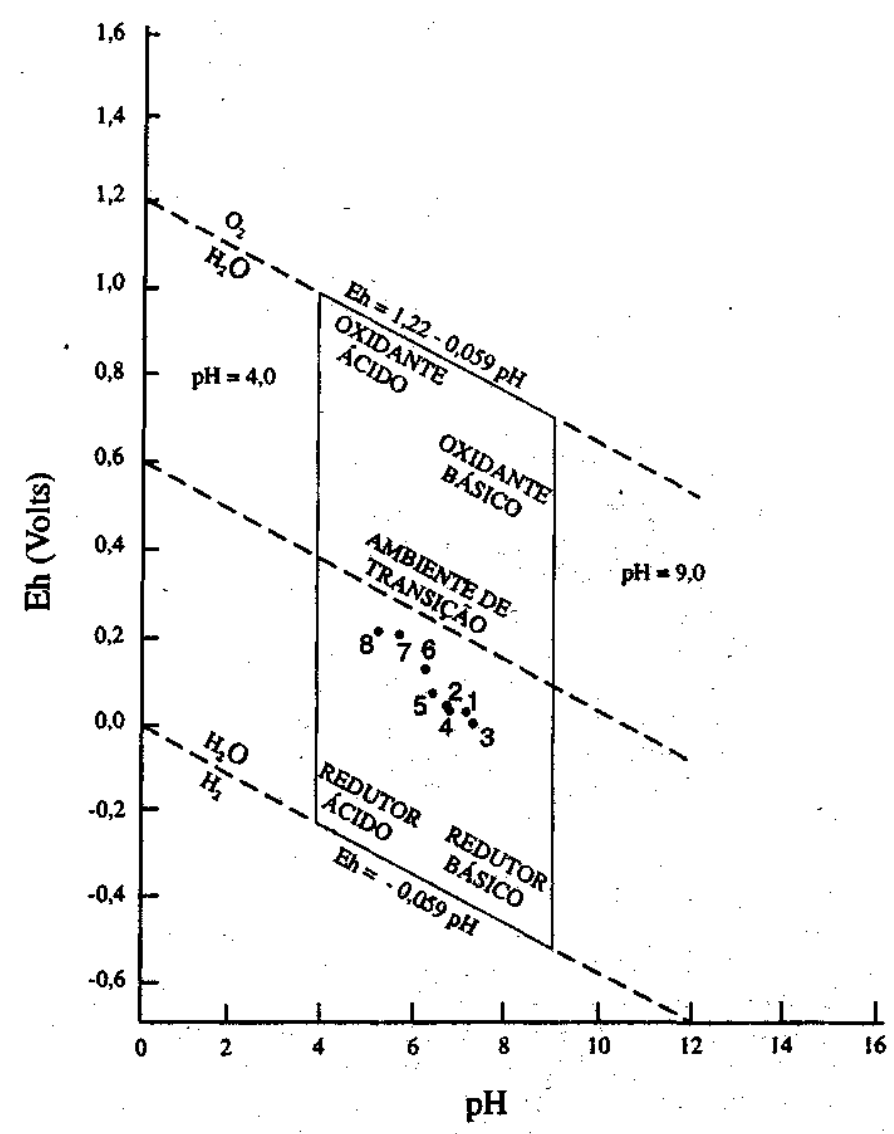

1-SÃO ROQUE

2-FILÒMENA

3-BELEZA

4-GLÓRIA

5 - SANTA ISABEL

6-LINDÁLIA

7 - LEVÍSSIMA I

8 - LEVÍSSIMA II

Figura 4- Representação no diagrama Eh-pH de Krauskopf (1972) dos dados obtidos para as águas subterrâneas de Águas de Lindóia.

Figure 4-Presentation of the data obtained for groundwaters from Águas de Lindóia (SP) in the Eh-pH diagram of Krauskopf (1972).

biológico por ser emissor alfa. Existem vários padrões nacionais para limitar a exposição devido ao ${ }^{226} \mathrm{Ra}$ nas águas potáveis. A máxima concentração permitida na água sugerida pela Organização Mundial de Saúde é de 10 pCi/1 (WHO 1972). O critério empregado no Brasil é baseado na Portaria No 36 de 19/01/90 do Ministério dá Saúde, a qual estabelece o valor de referência de 0,1 Bq/1 (cerca de 2,7 pCi/lXpara a radioatividade alfa total e de $1 \mathrm{~Bq} / 1$ para a radioatividade beta total.

A identificação dos radionuclídeos presentes nas águas e a medida de suas concentrações é prevista quando numa primeira avaliação os valores encontrados excedem os de referência para a radioatividade alfa e beta total, situação onde devem ser aplicados os critérios estabelecidos por CNEN (1988) para se concluir sobre a potabilidade da água; por exemplo, para $0^{238} \mathrm{U}$ e ${ }^{234} \mathrm{U}$, os limites de ingestão anual envolvendo os compostos inorgânicos de urânio solúveis em água correspondem, respectivamente, a $5 \times 10^{5}$ e $4 \times 10^{5} \mathrm{~Bq}$.
Como a maioria das águas analisadas são utilizadas para fins de consumo, pode-se empregar este padrão para avaliar sua potabilidade relativamente aos isótopos de urânio ${ }^{238} \mathrm{U}$ e ${ }^{234} \mathrm{U}$. O maior teor de urânio dissolvido corresponde a $0,51 \mu \mathrm{g} / 1$, determinado para a amostra da fonte Levíssima II. Assumindo uma ingestão diária média de 2 litros de água por indivíduo, e efetuando-se a apropriada conversão de unidade, obtém-se para esta amostra uma ingestão anual de ${ }^{238} \mathrm{U}$ igual a $4,6 \mathrm{~Bq}$ e de ${ }^{234} \mathrm{U}$ igual a 3,8 Bq. Quando a estimativa é efetuada para a amostra da fonte Lindália, para a qual se mensurou a maior ratão isotópica ${ }^{234} \mathrm{U} /{ }^{238} \mathrm{U}$, os valores correspondem a 0,5 e 2 $\mathrm{Bq}$, respectivamente, para ${ }^{238} \mathrm{U}$ e ${ }^{234} \mathrm{U}$. Dessa forma, constata-se que as atividades obtidas para as águas estudadas são consideravelmente inferiores às máximas permitidas, denotando sua potabilidade relativamente aos isótopos de urânio.

Razão Isotópica ${ }^{234} U /{ }^{238} U$ e prospecção Hidrogeoquímica de Urânio A interação áęua-rocha frequentemente resulta em razões de atividade ${ }^{234} \mathrm{U} /{ }^{238} \mathrm{U}$ para 0 urânio dissolvido maiores que a unidade (Osmond \& Cowart 1976). Vários mecanismos têm sido apontados como repensáveis pelo enriquecimento de ${ }^{234} \mathrm{U}$ na fase líquida:enfraquecimento da ligação de ${ }^{234} U$ nos retículos cristalinos dos minerais e oxidação preferencial, passando $0{ }^{234} \mathrm{U}$ do estado tetra para hexavalente, no qual se solubiliza prontamente na solução circulante (Chalov 1959); deslocamento do ${ }^{234} \mathrm{U}$ no retículo cristalino do mineral por ocasião do decaimento alfa do ${ }^{238} \mathrm{U}$, tendo em vista uma ação de recuo similar à do processo Szilard-Chalmers (Dooley et al. 1966); decaimento posterior do átomo de ${ }^{234} \mathrm{Th}$ recuado através da interface sólido-í́quido, em virtude do decaimento alfa do ${ }^{238} \mathrm{U}$ (Kigoshi 1971); remoção química dos núcleos de ${ }^{234} \mathrm{U}$ que penetraram os grãos vizinhos dos minerais, pela passagem de soluções naturais intergranulares (Fleischer 1980). Quando são consideradas as incertezas analíticas associadas à deter-

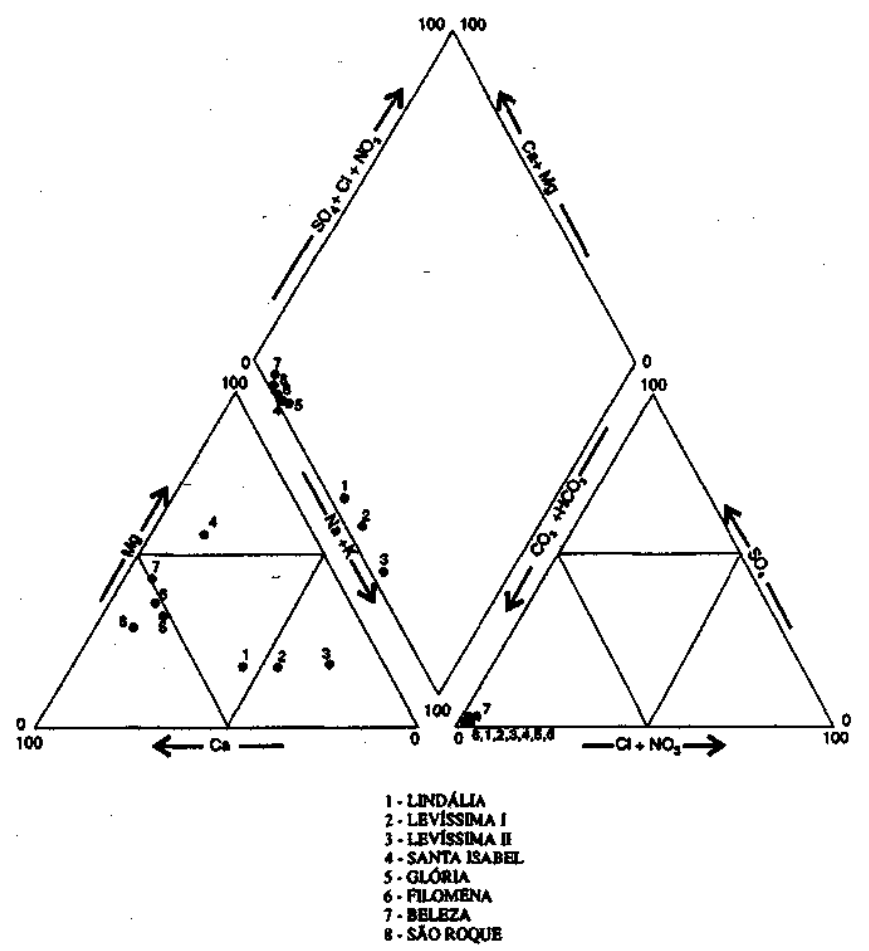

Figura 5- Representação no diagrama de Piper (1944) dos dados obtidos para as águas subterrâneas de Águas de Lindóia (SP),

Figure 5- Presentation of the data obtained for groundwaters from Águas de Lindóia (SP) in the Piper (1944) diagram. 


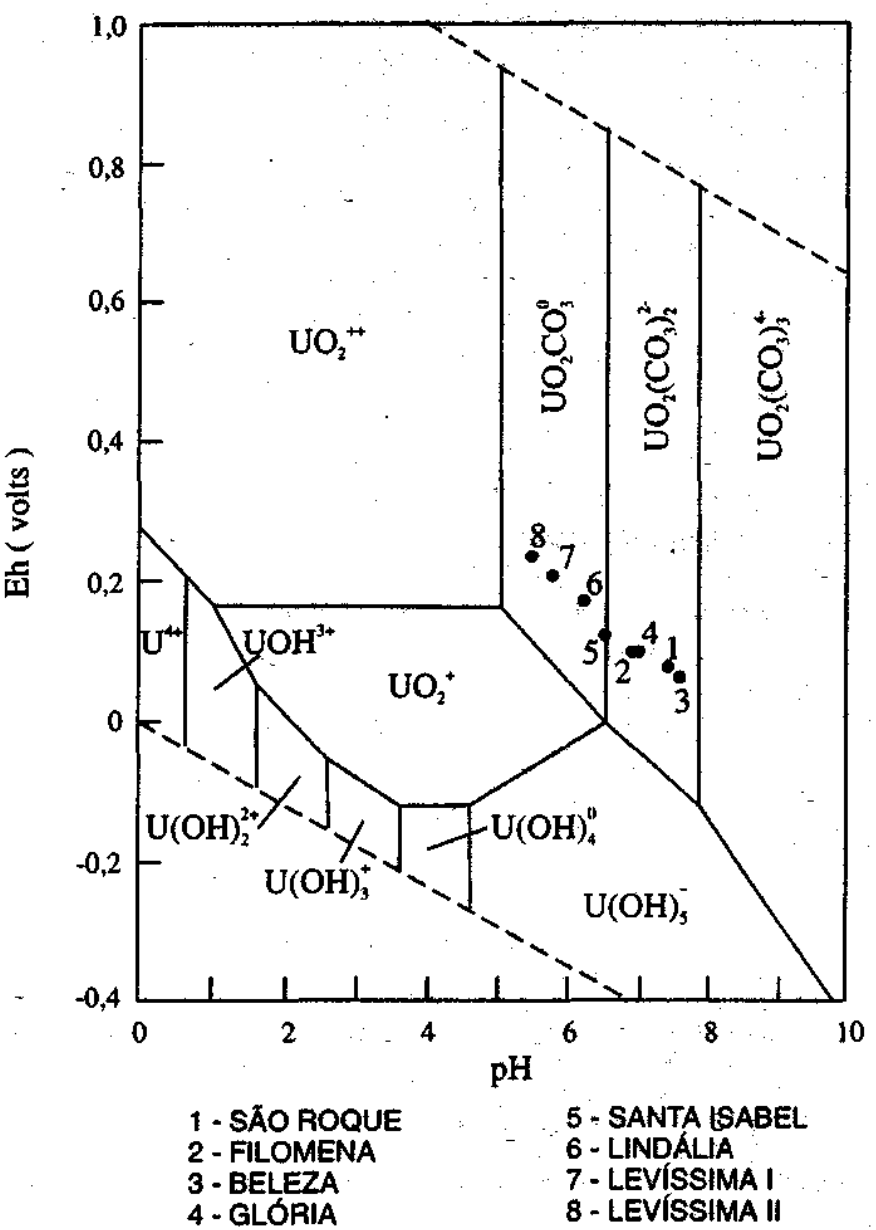

Figura 6- Representação dos dados obtidos para as águas subterrâneas de Águas de Lindóia (SP) no diagrama Eh-pH de Langmuir (1978) ilustrativo da importância relativa das valências $4+, 5+$ e $6+$ do urânio, a $25^{\circ} \mathrm{Cde}$ temperatura, $\Sigma U$ $=10^{-6} \mathrm{MePco}=10^{-2} \mathrm{~atm}$.

Figure 6- Presentation of the data obtained for grounwaters from Águas de Lindóia (SP) in the Eh-pH diagramof Langmuir (1978), showing the relative importance of $4+, 5+$ and $6+$ valenees of uranium at $25^{\circ} \mathrm{C}$ of temperature, $\Sigma \mathrm{U}$ $=10^{-6} \mathrm{M}$ and $\mathrm{Pco} 2=10^{-2} \mathrm{~atm}$.

minação das razões de atividade ${ }^{234} U /{ }^{238} U$ expressas na Tabela 1, observa-se que a maioria dos dados indica enriquecimento de ${ }^{234} \mathrm{U}$ em solução.

$\mathrm{O}$ teor de urânio dissolvido e razãaisotópica ${ }^{234} \mathrm{U} /{ }^{348} \mathrm{U}$ têm sido empregados para elaboração de modelos direcionados à prospecção hidrogeoquímica de depósitos de urânio. Cowart \& Osmond (1980) classificaram bidimensionalmente os sistemas de águas subterrâneas de acordo com esses parâmetros (Fig. 7). A terminologia acumulação refere-se a um teor de urânio na rocha do aquífero superior ao valor normal. Entre 1 e $10 \mathrm{ppb}$, situam-se os teores de urânio dissolvido característicos de aquíferos oxidantes que banham estratos portadores de concentrações médias de minerais uraníferos. Acima de 10 ppb, situam-sé os altos teores de urânio dissolvido, devido a presença de elevado conteúdo desse elemento nos estratos do aquífero. Abaixo de $1 \mathrm{ppb}$, situam-se os baixos teores de urânio dissolvido, indicativos de condições redutoras ou de estratos contendo baixas concentrações do elemento. A razão ${ }^{234} U /{ }^{238} U=0$ denota a ocorrência de ${ }^{234} U$ abaixo dos limites de detecção. Entre 1 e 2 situam-se as razões ${ }^{234} \mathrm{U} /{ }^{238} \mathrm{U}$ normais, obtidas pela maioria dos pesquisadores. Abaixo de

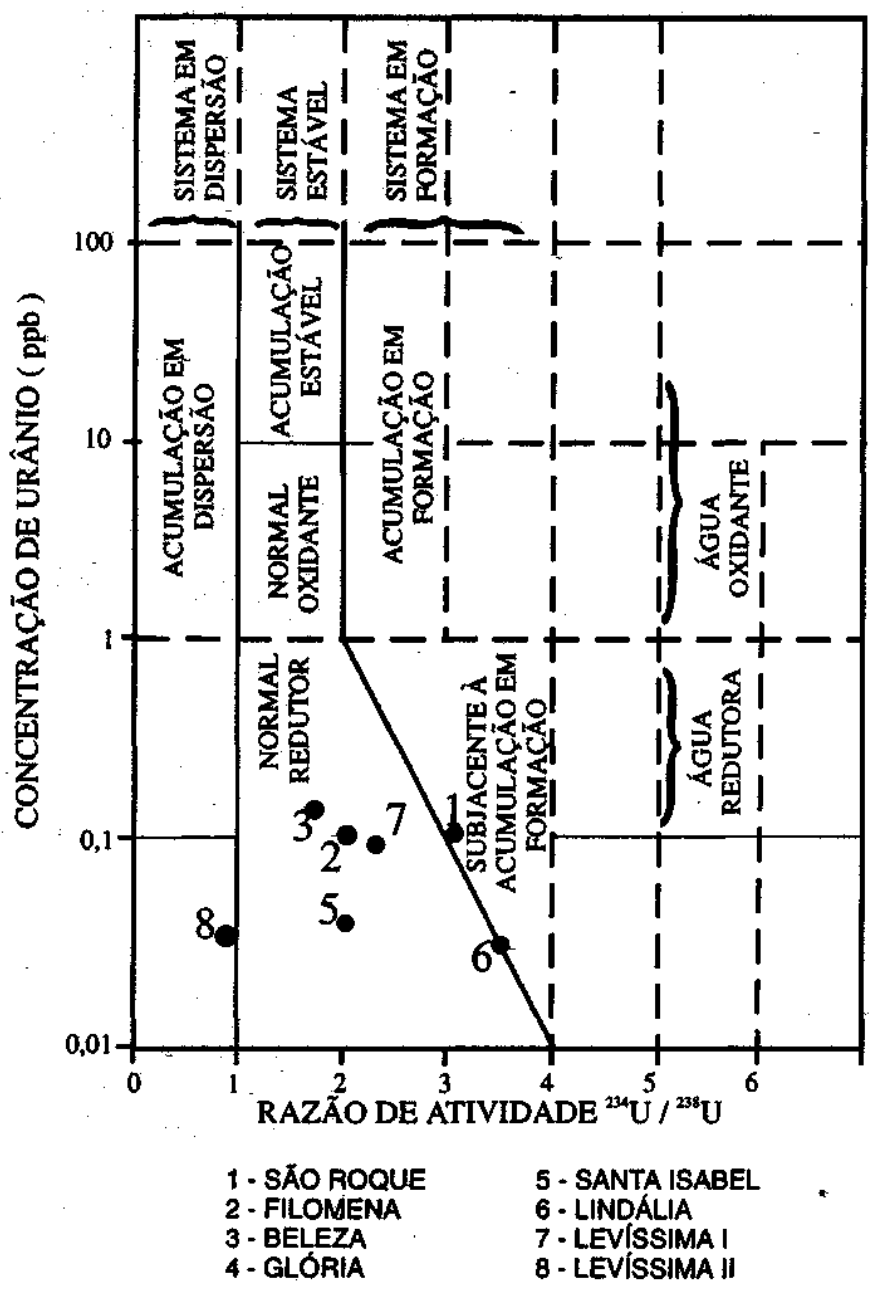

Figura 7- Representação dos dados obtidos para as águas subterrâneas de Águas de Lindóia (SP) no diagrama de Cowart \& Osmond (1980) ilustrativo da concentração de urânio e razão de atividade ${ }^{234} U{ }^{238} U$.

Figure 7- Presentation of the data obtained for grounwaters from Águas de Lindóia (SP) in the diagram of Cowart \& Osmond (1980), showing the uranium concentration and ${ }^{234} \mathrm{U} /{ }^{238} \mathrm{U}$ activity ratio.

1 situam-se as baixas razões ${ }^{234} \mathrm{U} /{ }^{238} \mathrm{U}$, anormais nas águas subterrâneas devido o efeito do recuo alfa e explicáveis a partir da remobilização da acumulação na escala de tempo de $10^{5}$ anos (acumulação em dispersão). Acima de 2 situam-se as altas razões ${ }^{234} \mathrm{U} /{ }^{238} \mathrm{U}$ originadas pela introdução de átomos de ${ }^{234} \mathrm{U}$ em solução devido o processo de recuo alfa, ocorrendo provavelmente onde o teor de urânio dissolvido na água diminui concomitantemente com o aumento de sua concentração no estrato hospedeiro (acumulação em formação). № caso da ocorrência de deposição de urânio nos estratos situados em zona redutora, em virtude do baixo teor de urânio dissolvido nas águas, há um aumento na probabilidade de obtenção de altas razões ${ }^{234} \mathrm{U} /{ }^{238} \mathrm{U}$, por se tornar significativa a adição de ${ }^{234} U$ à água pelo recuo alfa, mesmo sendo normais as concentrações dos minerais uraníferos nos estratos. A situação é designada de "subjacente à acumulação em formação" e a diagonal representada no diagrama visa aproximar essefator.

Os teores de urânio e razões isotópicas ${ }^{234} U /{ }^{238} U$ determinados para as águas estudadas foram inseridos no diagrama de Cowart \& Osmond (1980) ilustrado na Figura 7, para avaliar a sua aplicabilidade na área de Águas de Lindóia. 
Conforme se nota, pode-se atribuir a classificação "normal redutor" ao sistema hídrico estudado, significando que características redutoras predominam no ambiente de circulação das águas e que elas teriam lixiviado estratos contendo baixa concentração de urânio, isto é, não portadores de acumulação desse elemento. Assim, o modelo de Cowart \& Osmond (1980) denota ser aplicável na área por encontrar suporte nos outros dados apresentados nesse trabalho.

CONCLUSÃO O teor de urânio dissolvido nas águas subterrâneas de Águas de Lindóia (SP) variou de 0,001 a $0,509 \mathrm{ppb}$, enquanto que a razão de atividade ${ }^{234} \mathrm{U} /{ }^{238} \mathrm{U}$ para as fontes estudadas situou-se entre 0,81 e 3,76, correspondendo ao intervalo de variação de 1 a 2 obtido pela maioria dos pesquisadores. Esses resultados mostram que os isótopos de urânio ${ }^{234} \mathrm{U}$ e ${ }^{238} \mathrm{U}$ estão sendo mobilizados nos aquíferos em virtude dos processos deinteração água-rocha. Constatou-se que é alta a pressão parcial de $\mathrm{O}_{2}$ dissolvido nas águas de todas as fontes estudadas, praticamente correspondendo à pressão parcial do oxigénio em água saturada de ar; apesar disso, o ambiente de circulação das águas apresenta características predominantemente redutoras, denotando não existir relação entre o potencial redox Eh e o teor de oxigénio dissolvido. A avaliação da pressão parcial de $\mathrm{CO}_{2}$ dissolvido nas águas permitiu constatar que o valor médio corresponde ao valor típico registrado para as águas subterrâneas. O efeito desse parâmetro na dissolução de urânio mostrou ser de importância, pois sugeriu que o urânio pode estar sendo transportado na forma dos complexos $\mathrm{UO}_{2} \mathrm{CO}_{3}{ }^{0}$ e $\mathrm{UO}_{2}\left(\mathrm{CO}_{3}\right)_{2}{ }^{2-}$. Os dados isotópicos de urânio para as águas analisadas permitiram avaliar modelo disponível em literatura para a p/ospecção geoquímica de depósitos de urânio na área de Águas de Lindóia, o qual mostrou-se satisfatório para a interpretação dos resultados obtidos, não evidenciando a presença de acumulação de urânio nos estratos lixiviados pelas águas.

Agradecimentos Os autores expressam seus sinceros agradecimentos aos revisores anônimos pelos comentários construtivos.

\section{REFERÊNCIAS}

ALMEIDA, F.F.M. \& HASUI, Y. 1984. O pré-cambriano do Brasil. São Paulo, Editora Edgard Blücher. $378 \mathrm{p}$.

BLANCHARD, R.L. $1965 .{ }^{234} \mathrm{U} /{ }^{238} \mathrm{U}$ ratíos in coastal marine water and calcium carbonates. J. Geophys. Rés., 70:4055-4061.

BONOTTO, D.M. 1986. Aplicaç̃̃es hidrogeoquímicas dos isótopos naturais das séries doU(4n+2)e Th (4n) no Morro do Ferro, Pocos de Caldas $(M G)$. São Paulo, 377 p. (Tese de Doutorado, Universidade de São Paulo).

BROWNLOW, H.A. 1979. Geochemistry. Boston, Prentice-Hall. 498 p.

CHALOV, P.1.1959. Isotopic ratio of ${ }^{234} \mathrm{U} /{ }^{238} \mathrm{U}$ in some seconday minerais. Geochemistry, 2:203-210.

CHERDYNTSEV, V.V.; KAZACHEVSKII.IV ; KUZ'MINA, E.A. 1955. Dating of pleistocene carbonate formation by thoríum and uranium isotopes. Geochem. Intern., 794-801.

CNEN (Comissão Nacional de Energia Nuclear) 1988. Diretrizes básicas de radioprotecão. Rio de Janeiro. 129 p. (Resolução 12/88),

COWART, J.B. \& OSMOND, J.K. 1980. Uranium isotopes in groundwater asaprospecting technique. Colorado, U S Dept. of Energy. $112 \mathrm{p}$

DAEE (Departamento de Águas e Energia Elétrica) 1981. Estudo das águas subterrâneas. Região administrativa 5-Campinas. São Paulo, Secretaria de Obras e do Meio Ambiente, v. 1,627 p.

DEL REY, A.C. 1989. Estudo hidrogeotérmico da região de Águas de Lindóia, Amparo e Socorro-nordeste do Estado de São Paulo. São Paulo, 124 p. (Dissertação de Mestrado, Universidade de São Paulo).

DNPM (Departamento Nacional da Producão Mineral) 1987. Perfil analítico das águas minerais. Brasília. 49p (Boletim).

DNPM (Departamento Nacional da Produção Mineral) 1988. Anuário mineral brasileiro. Brasília, p. 118-120.

DOOLEY, J.R.; GRANGER, H.C.; ROSHOLT, J.N. 1966. Uranium-234 fractionation in the sandstone-type uranium deposits of the Ambrósia Lake District, New México. Economic Geology. 61:1362-1382.

FAURE G. 1991. Principies and applications of Inorganic Geochemistry. New York, MacMillan Publishing Company. $626 \mathrm{p}$.

FENZL, N. 1988. Introdução à hidrogeoquímica. Belém, Universidade Federal do Pará. $190 \mathrm{p}$

FLEISCHER, R.L. 1980. Isotopic disequilibrium of uraniunralpha-recoil damage and preferential solution effects. Science, 207:979-981.

GARRELS, R.M. 1960. Mineral equilibrio at low temperature andpressure New York, Harper \& Brothers, 254p.

GOLDSCHMIDT, V. M. 1954. Geochemistry. Oxford, Clarendon Press. $730 \mathrm{p}$.

GROSSISAD, J.H.; LICÍNIO, A.; BARBOSA, M.; MENEZES PIVA, J.A.; ROLIM, V.K.; PINTO, C.P. 1982. Geologia e recursos minerais da Folha Socorro, São Paulo, Brasil. São Paulo, Secretaria da Indústria, Comércio e Ciência Tecnológica, Programa de Desenvolvimento de Recursos Minerais Pró-Minério. 287 p.
HEM, J. D. 1959. Study and interpretation of the chemical characteristics of natural water. Geológica! Survey Water-Supply Paper, 1473:1-269.

HURTER, J.S. 1988. The use of chemical geothermometry and heat loss models in estimating terrestrial heat flow for low-temperature hydrothermal systems. Rev. Bros. Geof., 6 (2):33-42.

KIGOSHI, K. 1971. Alpha-recoil Thorium-234:dissolution into water and the Uranium-234 / Uranium-238 disequilibrium in nature. Science, 173:47-48.

KRAUSKOPF, K.B. 1972. Introdução à Geoquímica. São Paulo, Editora Polígono S.A. v. 2,311p.

LANGMUIR, D. 1978. Uranium solution-mineral equilibria at low temperatures with applicatíons to sedimentary ore deposits. Geochim. Cosmochim. Acta, 42:547-569.

MIYAKE, Y.; SUGIMURA, Y.; UCHIDA, T. 1966. Ratio ${ }^{234} U /{ }^{238} U$ and the uranium concentration in seawater in the westem North Pacific. / Geophys. Res. .71:3083-3087.

MOORE, W.S. \& SACKETT, W.M. 1964. Uranium and thorium series inequilibrium in sea water. J. Geophys. Res., 69:5401-5405.

OSMOND, J.K.; RYDELL, H.S.; KAUFMAN, MJ. 1\%8. Uranium disequilibrium in groundwateran isotope dilution apprpach in hydrologic investigations. Science, 162:997-999.

OSMOND, J.K. \& COWART, J.B. 1976. The theory and uses of natural uranium isotopic variations in Hydrology. At. Energy Rev., 14:621-679.

OSMOND, J.K. \& IVANOVICH, M. 1983. Uranium isotopic disequilibrium in groundwater as an indicator of anomalies. Int App. Radiat. Isot., 34 (1):283-308.

PIPER, A.M. 1944. A graphic procedure in the geochemical interpretation of water-analyses. Trans. Amer. Geophysical Union, 25:914-928.

RÒSLER, H.J. \& LANGE, H. 1972. Geochemical tables. Amsterdam, Elsevier. $468 \mathrm{p}$.

STUMM, W. \& MORGAN, J.J. 1970. Aquatic Chemistry-An Introduction Emphasizing Chemical Equilibria in Natural Waters . New York, Wiley. $583 \mathrm{p}$.

TODD, D. K. 1980. Groundwater Hydrology. New York, Wiley. 2nd ed., 535 P.

WHO (World Health Organization) 1972. Protection against ionizing radiations: a survey of current world legislation. Geneva. $328 \mathrm{p}$.

YOSHINAGA, S. 1990. Estudos hidrogeológicos, hidrogeoquímicos e isotópicos das águas minerais e termais de A guas de Lindóia, SP. São Paulo, 270p. (Dissertação de Mestrado, Universidade de São Paulo).

MANUSCRITO A844

Recebido em 04 de abril de 1996

Revisã o dos Autores em 27 de novembro 1996 Revisã 0 aceita em 30 de novembro de 1996 